\title{
Wastewater sewage sludge: the thermal treatment solution
}

\author{
D. Panepinto \& G. Genon \\ DIATI Department, Politecnico di Torino, Italy
}

\begin{abstract}
The right individuation of a more convenient solution for the final treatment and destination of sewage sludge is a very interesting problem, in account of the urgent need for acceptable solutions.

In this work we examined, both from a technological and from an environmental point of view, the thermal solutions (firstly the direct combustion in incineration plant, but also gasification) for the sludge deriving from the main Italian wastewater plant (plant of the metropolitan area of Torino).

In order to arrive at a solution, an initial analysis was necessary in order to define the main characteristics of the produced sludge (flow rates, composition); afterwards we analyzed the potential plant design solutions in detail in order to arrive at some prospective indications.

Keywords: energy recovery, sludge thermal treatment, incineration, gasification.
\end{abstract}

\section{Introduction}

The production of sewage sludge from wastewater treatment is continuously increasing; taking also into account the high amount of difficulty normally encountered in the sludge disposal, the individuation of innovative strategies or the optimization of the conventional existing systems for their final management seem to be very important tasks.

The produced sludge, if it has been subjected to thermal drying, is suitable for energetic valorization processes as, for example, direct combustion in an incineration plant but also innovative systems such as gasification and pyrolysis $[1,2,10,11,14]$.

These processes present the very important positive aspects, which lead to the correct management for the disposal problem; at the same time they can represent a useful energy source. 
From this point of view it is important to consider that, in opposition to the continuously increasing difficulty to generate energy from traditional fossil sources, the possibility to obtain energy from biomass (as for example from the sewage sludge) represents an interesting tool both for the reason that this source is certainly renewable and corresponding to the directives of the Kyoto protocol, and also for economical aspects (in fact the energy that is derived from traditional sources presents an ever-increasing cost).

On the basis of these considerations the aim of the present work is the individuation of the optimal solution (in particular with a thermal treatment approach), for the correct disposal of the sewage sludge deriving from wastewater treatment, with particular reference to a specific large-scale example.

With this aim after an initial cognitive analysis directed to define the main qualitative and quantitative characteristics of the produced sludge we analyzed some proposed design plant solutions (thermal treatment with direct combustion in incineration plant and gasification), by considering technical and processing points of view.

\section{State of the art}

The main technologies for wastewater sewage sludge management are outlined in the following $[7,9,10]$ :

- immission in landfill: the positive aspect is the real limitation of the environmental impact taking into account the necessity of sludge treatment and stabilization before the immission. From the other hand the negative aspects are, in particular, the normative trend (D. Lgs. 36/2003) that foresee the use of landfill only for residual wastes and the difficulty to find new sites in order to allocate the wastes;

- $\quad$ agriculture use: from an environmental point of view this is a real organic substances reuse, the main disadvantages are, first of all, the possible presence of toxic accumulative substances (such as, for example, heavy metals but also micro pollutants as IPA or PCB) and furthermore it is not easy to find the correspondence between the necessity of disposal and the availability of agriculture sites in the different periods of the year;

- thermal treatment: in this case the management positive aspect is that this treatment is an independent solution. By analyzing the literature $[11-13,15]$ we can see that are, in particular, three main solutions for the thermal options:

o incineration in dedicated plant: this is the solution today more widespread in the North of Europe, on the medium realization scale;

o incineration with MSW: generally sludge-MSW rate is 1:5, 1:10, and the combustion are developed in conventional grate system;

0 incineration in cement kiln or in other energetic production plant.

By analyzing the information present in literature [8] we can see that the technology today more promising for the wastewater sludge treatment is the technology of thermal treatment and in particular direct combustion in fluidizing bed at atmospheric pressure. 


\section{Presentation of the specific considered situation}

The considered wastewater plant is actually the biggest present plant in Italy: the plant in fact is able to receive until to $16 \mathrm{~m}^{3} / \mathrm{s}$ of sewage. The following sections are present in the plant: primary treatment, secondary (biological) and tertiary (physic-chemical) sections; energetic recovery systems operating on the produced sludge are directed to the cogeneration of thermal and electric energy, for about 60 millions of $\mathrm{kWh} / \mathrm{y}$.

The annually treated wastewater of the plant corresponds to about $200,000,000 \mathrm{~m}^{3} / \mathrm{y}$.

As it was indicated, the plant is composed of two lines: the "water line" where the physical, chemical and biological treatment required to eliminate all the pollutants present in the wastewater are used; from there the treated water is discharged in the river, or alternatively it can be reused for industrial use; the complementary "sludge line" is formed by all the plants required for the correct final treatment of the biological sludge arising from the treatments operating into the "water line", before the final disposal.

The sludge line capacity corresponds to about $6,000 \mathrm{~m}^{3} / \mathrm{d}(2 \%$ d.s. $)$; the maximum daily treated flow is equal to about $12,000 \mathrm{~m}^{3} / \mathrm{d}$.

The process is formed by different phases, the first (and the main), after the sludge thickening corresponds to the anaerobic digestion; subsequently there are three different treatments for mechanical or thermal drying, with production of centrifuged sludge, filtered sludge and thermally dried sludge.

Table 1: $\quad$ Flow rates of the different types of sludge coming from treatment.

\begin{tabular}{|l|l|l|l|}
\cline { 2 - 4 } \multicolumn{1}{c|}{} & centrifuged & filtered & therm. dried \\
\hline Product sludge $[\mathrm{kg} / \mathrm{y}]$ & $40,810,760$ & $53,736,150$ & $5,741,352$ \\
\hline$\%$ d.s. & 29 & 41 & 90 \\
\hline Dry sludge [kg d.s. $/ \mathrm{y}]$ & $11,873,988$ & $22,031,822$ & $5,193,823$ \\
\hline
\end{tabular}

\section{Analytical definition of the sludge}

In order to arrive at a useful understanding of the composition of the sludge, required to establish the right final treatment scheme, we performed the determination of some analytical parameters referring to the three typologies of the produced sludge: the considered parameters have been the concentration of metals, the chlorine and the sludge heating lower value.

For the metals parameters, we proceeded to the collection and interpretation of the obtained values (present in the data-base of the plant control lab) of a time period of two years, in order to arrive to significant and consistent data.

The elaborations led to some statistical analysis (maximum, minimum and medium value), able to represent for these parameters a true range. 
As concerns the chlorine parameter, we performed its analytical definition (there are not historical series data for this parameter); in order to do this we used different methodologies for the samples preparation and for the instrumental analysis.

All the sludge analyzed samples were submitted to two different preparative phases, i.e. leaching in water or acid attack (the acid digestion has been realized into the microwave oven or into an equipment operating with condense fall out).

The analytical part has been divided in two phases: for the samples leading to a solution with high concentration (more than $5 \mathrm{mg} / \mathrm{l}$ ) we proceeded with the volumetric analysis (precipitation titration with the Vohlard method); for concentrations between $1 \mathrm{mg} / \mathrm{l}$ and $5 \mathrm{mg} / \mathrm{l}$ on the contrary we proceeded with a spectrophotometric determination.

As concerns the lower heating value determination, the value has been defined with a calorimetric apparatus.

Known quantities of the sludge samples were combusted in a Mahler bomb after calibration with benzoic acid. The tests, in multiply repetition, have demonstrated a good repeatability of the analytical data and a numerical value constancy for all the samples at disposition.

In Table 2 we can see the qualitative results for the three analyzed sludge types.

\section{Thermal solution}

As it was anticipated, recently the attention has been focused in the direction of thermal treatments for the sludge deriving from treatment, also for considerations connected to reasons of energy recovery.

These solutions may be the most rational in the sewage sludge final treatment evaluation, with the condition that they are accompanied by reliable technologies as concerns energy recovery and containment of pollution. By this way the advantages produced by these plants can be completely exploited, in particular with reference to the very low requirement of space, the elimination of odorous emissions and the reduction of mass and of potential impact for the final sludge disposal.

The thermal treatments are operating by high-temperature chemical processes, where the organic sludge components are demolished to give more simple gaseous products. The primary aim of each thermal treatment is therefore the transformation of the material in a form less harmful for the environment and for the humans, with consequent reduction of the amount of substances to be sent to final disposal; secondly an energy recovery in the form of electricity and / or heat can be obtained.

The thermal treatments are essentially constituted by $[1,3-6,14,16]$ :

- incineration;

- gasification;

- pyrolysis;

- plasma gasification. 
Table 2: Main sludge characteristics.

\begin{tabular}{|c|c|c|c|}
\hline & centrifuged & filtered & therm. dried \\
\hline $\begin{array}{l}\text { Product sludge } \\
{[\mathrm{kg} / \mathrm{y}]}\end{array}$ & $40,810,760$ & $53,736,150$ & $5,741,352$ \\
\hline$\%$ d.s. & 29 & 41 & 90 \\
\hline $\begin{array}{l}\text { Dry sludge [kg d.s. } \\
\text { /y] }\end{array}$ & $11,873,988$ & $22,031,822$ & $5,193,823$ \\
\hline LHV [kcal/kg] & 390 & 660 & 2.770 \\
\hline \multicolumn{4}{|l|}{$\begin{array}{l}\text { Composition } \\
{[\mathrm{mg} / \mathrm{kg} \text { d.s.] }}\end{array}$} \\
\hline $\mathrm{Al}$ & $9,600-20,000$ & $4,100-13,000$ & $11,000-21,000$ \\
\hline As & $5.2-9.2$ & $1-6.8$ & $5.3-8.6$ \\
\hline $\mathrm{C}[\%$ d.s. $]$ & $25-34$ & $10-32$ & $27-34$ \\
\hline $\mathrm{Cr}$ & $210-410$ & $150-330$ & $240-420$ \\
\hline $\mathrm{Cu}$ & $300-530$ & $100-600$ & $339-570$ \\
\hline $\mathrm{Fe}$ & $48,000-61,000$ & $46,000-72,000$ & $44,000-61,000$ \\
\hline $\mathrm{Hg}$ & $1-2.3$ & $1-1.3$ & $1-2.3$ \\
\hline $\mathrm{N}[\%$ d.s. $]$ & $2.7-4.5$ & $1-4.4$ & $3.5-5$ \\
\hline $\mathrm{Ni}$ & $140-270$ & $80-210$ & $150-280$ \\
\hline $\mathrm{P}$ & $2.3-2.9$ & $1.1-3$ & $2.3-3.1$ \\
\hline $\mathrm{Pb}$ & $1-260$ & $38-180$ & 93-190 \\
\hline $\mathrm{Zn}$ & $1,444-4,200$ & $500-3,400$ & $1,000-2,000$ \\
\hline $\mathrm{S}[\%$ d.s. $]$ & $0.93-1.3$ & $0.19-1.1$ & $0.88-1.4$ \\
\hline Cl total & $600-900$ & $2,000-3,000$ & $700-1,000$ \\
\hline $\mathrm{Cl}$ organic & & & $200-300$ \\
\hline $\mathrm{Cl}$ inorganic & & & $500-700$ \\
\hline $\begin{array}{l}\text { Total volatile solid } \\
{[\% \text { t.q.] }}\end{array}$ & $11-18$ & $2-16$ & $39-57$ \\
\hline Total solid [\% t.q.] & $23-35$ & $27-48$ & 78-98 \\
\hline
\end{tabular}

Among these alternatives the incineration is certainly the most diffused and applied operation, and the experience on industrial scale is certainly large; the other treatments (in particular the gasification) are proposed (and there is important activity of development) as technological alternative to the incineration systems.

All the treatments, and in particular the gasification system, must be fundamentally evaluated from two points of view: from one side with reference to the energetic balance, and from the other side with reference to the capacity to generate secondary pollutants. 
From the point of view of the first point, the aspects that must be considered are:

- thermal energy that is required in the preliminary sludge drying treatment;

- thermal energy that can be obtained from the final treatment of the dried sludge;

- transformation of the generated thermal energy in electric energy and/or heat.

The interaction of these energy fluxes lead to the total energy plant efficiency. As concerns the specific terms, it must be considered that for the first term it is required to correctly evaluate the initial and final humidity of the sludge, for the second in the direct combustion is fundamental to know the lower heating value of the material sent to the furnace, and the energetic transfer efficiency for the produced heat.

In the gasification case the yield of transformation in syngas and the gasification energetic efficiency are fundamental, and subsequently it must be carefully considered the thermal production capacity in the syngas combustion.

Downstream of the drying optimal level choice (deriving from a balance between a higher thermal energy that is spent during the drying phase and a higher energy capacity that is subsequently obtained in the dried energetic valorization), it is important to establish an energetic balance comparison between the direct combustion in incineration plant and an alternative gasification system.

On the basis of the specific sludge quality data that in the particular case must be taken into account, and also of literature values for the energy transformation parameters, it is possible to evaluate the results of the energy balance process in the two above reported configurations.

As concerns the environmental impact, there are literature data referring to the pollutant formation capacity in correlation with different thermal treatments (emission factors for the transfer of primary pollutants from gaseous flow, formation of nitrogen oxides and dust); also in this case the results must be considered both for the direct combustion and for gasification; with reference to the particular considered case, by taking into account this basic information it is possible to define the polluting capacity of thermal treatment system.

As concerns the operative aspects, by analyzing the information that is present in the literature we can see that thermal treatment technology is the most used and tested method today and therefore what seems to be more reliable is the direct incineration into a fluidized bed at atmospheric pressure. For this reason, this solution will be more deeply considered in this paper. Nevertheless, by considering the innovative aspects and the promises for the gasification, this technology will also be considered for a proposal of application.

\subsection{Analysis of the systems}

On the basis of the defined data concerning sludge quantities and analytical characteristics it was possible to proceed with the elaboration of an incineration hypothesis. 
The sludge, after being stored in silos or in bunkers of suitable volume, is fed into the fluidized bed incinerator (FBI) from one side with a spreader system. The FBI consists of a cylindrical refractory lined steel shell. In the lower part of the vertically arranged incinerator a nozzle grate is installed serving for the distribution of the fluidizing air. Above the nozzle grate, a sand bed is kept in fluidized motion by introduction of up flowing air through the nozzle grate. A post reaction zone is arranged above the fluidized bed. The sludge is fed to the fluidized bed from above, it disintegrates, the water evaporates, the sludge then ignites and the volatile components burn out completely during the retention time of solids and afterwards of flue gas in the combustion zone. The inorganic matter is pulverized to ash and leaves the incinerator together with the flue gas at the top. At the outlet of the FBI a waste heat recovery system is installed.

The flue gas is subjected to a flue gas treatment comprising the following process steps:

- electrostatic precipitator for the removal of dust;

- 2-stage wet scrubbing system for the removal of acid gases and heavy metals;

- re-heating of flue gas to $120^{\circ} \mathrm{C}$;

- polishing bag filter with dry adsorption process or removal of remaining concentrations of heavy metals, acid gases and dust by dosing of pulverized activated carbon (PAC) and lime.

The plant will be designed to operate $8000 \mathrm{~h} / \mathrm{y}$ with a sewage sludge input of $100290 \mathrm{t} / \mathrm{y}$ (38.9\% DS).

In Table 3 we report the results of a performed test that used the flue gas treatment as described above.

We calculated the mass and energy balance and the values are reported in Table 4.

Table 3: Value derived from performing the test.

\begin{tabular}{|l|l|l|}
\hline Parameters & Value & Measure Unit \\
\hline Particultaes & $<1$ & $\mathrm{mg} / \mathrm{Nm}^{3}$ \\
\hline $\mathrm{TOC}$ & $<1$ & $\mathrm{mg} / \mathrm{Nm}^{3}$ \\
\hline $\mathrm{HCl}$ & $<1$ & $\mathrm{mg} / \mathrm{Nm}^{3}$ \\
\hline $\mathrm{HF}$ & $<1$ & $\mathrm{mg} / \mathrm{Nm}^{3}$ \\
\hline $\mathrm{SO}_{2}$ & $<1$ & $\mathrm{mg} / \mathrm{Nm}^{3}$ \\
\hline $\mathrm{NO}_{\mathrm{x}}$ as $\mathrm{NO}_{2}$ & 43 & $\mathrm{mg} / \mathrm{Nm}^{3}$ \\
\hline $\mathrm{CO}$ & 16 & $\mathrm{mg} / \mathrm{Nm}^{3}$ \\
\hline $\mathrm{Cd}+\mathrm{Tl}$ & 0.00024 & $\mathrm{mg} / \mathrm{Nm}^{3}$ \\
\hline $\mathrm{Hg}$ & 0.007 & $\mathrm{mg} / \mathrm{Nm}^{3}$ \\
\hline $\mathrm{Sb}, \mathrm{As}, \mathrm{Pb}, \mathrm{Cr}, \mathrm{Co}, \mathrm{Cu}, \mathrm{Mn}, \mathrm{Ni}, \mathrm{V}$ & 0.03 & $\mathrm{mg} / \mathrm{Nm}^{3}$ \\
\hline $\mathrm{PCDD}+\mathrm{PCDF}($ as $\mathrm{TE})$ & 0.0023 & $\mathrm{ng} / \mathrm{Nm}^{3}$ \\
\hline
\end{tabular}


Table 4: Main sludge characteristics.

\begin{tabular}{|c|c|c|}
\hline \multicolumn{3}{|c|}{ Incineration } \\
\hline Sludge feed rate & $\mathrm{kg} / \mathrm{h}$ & 12,500 \\
\hline Sludge feed rate (DS) & $\mathrm{kg} / \mathrm{h}$ & 4,900 \\
\hline Retention time & $\mathrm{s}$ & $>2$ \\
\hline $\mathrm{O}_{2}$ content & $\%$ dry base & 8.0 \\
\hline Fluidizing air & $\mathrm{Nm}^{3} / \mathrm{h}$ & 19,300 \\
\hline Air temperature & ${ }^{\circ} \mathrm{C}$ & 500 \\
\hline Cooling air & $\mathrm{Nm}^{3} / \mathrm{h}$ & 3,000 \\
\hline Flue gas & $\mathrm{Nm}^{3} / \mathrm{h}$ & 33,200 \\
\hline Temperature & ${ }^{\circ} \mathrm{C}$ & $850-950$ \\
\hline Thermal load & MW & 8.35 \\
\hline \multicolumn{3}{|c|}{ Heat recovery and electric energy production } \\
\hline Flue gas & $\mathrm{Nm}^{3} / \mathrm{h}$ & 33,200 \\
\hline Flue gas temperature & ${ }^{\circ} \mathrm{C}$ & $900 / 200$ \\
\hline Air flow & $\mathrm{Nm}^{3} / \mathrm{h}$ & 19,300 \\
\hline Air temperature in/out & ${ }^{\circ} \mathrm{C}$ & $120 / 500$ \\
\hline Steam flow & $\mathrm{kg} / \mathrm{h}$ & 9,900 \\
\hline Steam temperature & ${ }^{\circ} \mathrm{C}$ & 400 \\
\hline Steam pressure & bar & 41 \\
\hline Electrical power & $\mathrm{kW}$ & 920 \\
\hline \multicolumn{3}{|c|}{ Chemicals, utilities and residuals } \\
\hline $\mathrm{NaOH}$ at $47 \%$ (for removal of $\mathrm{SO}_{2}$ ) & $\mathrm{kg} / \mathrm{h}$ & 250 \\
\hline $\mathrm{NH}_{3}$ at $25 \%$ (for removal of $\mathrm{NO}_{\mathrm{x}}$ ) & $\mathrm{kg} / \mathrm{h}$ & some \\
\hline $\begin{array}{c}\text { PAC/lime at } 15 \% \mathrm{C} \text { (for removal of } \\
\text { heavy metals }-\mathrm{Hg} \text { ) }\end{array}$ & $\mathrm{kg} / \mathrm{h}$ & 20 \\
\hline Electrical power & $\mathrm{kWh} / \mathrm{h}$ & 920 \\
\hline Potable water & $\mathrm{m}^{3} / \mathrm{d}$ & 5 \\
\hline Quartz sand & $\mathrm{kg} / \mathrm{d}$ & $\begin{array}{l}\text { Depends on incoming } \\
\text { sludge quantity }\end{array}$ \\
\hline Natural gas & $\mathrm{Nm}^{3} / \mathrm{h}$ & 650 \\
\hline $\begin{array}{l}\text { Final effluent for cooling (mainly } \\
\text { turbine and scrubber) at } 15^{\circ} \mathrm{C}\end{array}$ & $\mathrm{m}^{3} / \mathrm{h}$ & 800 \\
\hline Poly electrolyte & $\mathrm{g} / \mathrm{h}$ & 20 \\
\hline TMT 15 & $1 / \mathrm{h}$ & 1 \\
\hline $\mathrm{FeCl}_{3}$ & $\mathrm{~g} / \mathrm{h}$ & 250 \\
\hline Ash & $\mathrm{kg} / \mathrm{h}$ & 1,900 \\
\hline Spent PAC/lime & $\mathrm{kg} / \mathrm{h}$ & 25 \\
\hline Effluent from boiler blow down & $\mathrm{m}^{3} / \mathrm{h}$ & 1 \\
\hline
\end{tabular}




\subsection{Literature gasification project}

In the following we report a literature example of sludge gasification in a fluidized bed reactor. In this case the sludge is different in comparison of the case of incineration. The features of the wastewater sewage sludge are reported in Tables 5 and 6.

In Figure 1 we can see the process scheme.

In Table 4 we report the main quantitative features of the sludge fed to the plant; these features are very important for the mass and energy balance development, as can be seen in the following Table 6 where the results of these balance are reported.

In Table 7 we can see the results of the energy balance that can be obtained by applying the energetic gasification asset (the yield reported in Table 6) to the studied wastewater sludge plant.

Table 5: $\quad$ Feedstock composition.

\begin{tabular}{|c|c|}
\hline Carbon & 54.26 \\
\hline Hydrogen & 8.67 \\
\hline Oxygen & 32.43 \\
\hline Nitrogen & 4.65 \\
\hline Sulphur & 0.96 \\
\hline Chlorine & 0 \\
\hline LHV (MJ/kg) & 20.42 \\
\hline \multicolumn{2}{|c|}{ Prox Anal (wt $\%$ ar) } \\
\hline Moisture & 25 \\
\hline Ash & 18.78 \\
\hline
\end{tabular}

Table 6: Technical performance.

\begin{tabular}{|l|l|}
\hline Thermal input $(\mathrm{kJ} / \mathrm{s})$ & 5,740 \\
\hline Engine output $(\mathrm{kW})$ & 1,130 \\
\hline Fan $(\mathrm{kW})$ & 45 \\
\hline Solid separation $(\mathrm{kW})$ & 20 \\
\hline Conveyer $(\mathrm{kW})$ & 30 \\
\hline Total $(\mathrm{kW})$ & 95 \\
\hline Net power output $(\mathrm{kWe})$ & 1,035 \\
\hline Thermal output $(\mathrm{kWth})$ & 2,787 \\
\hline Efficiency $($ electric), \% (LHV) & 18.03 \\
\hline Efficiency (CHP), \% (LHV) & 66.58 \\
\hline Capital cost (1000's Euro) & 2,697 \\
\hline
\end{tabular}




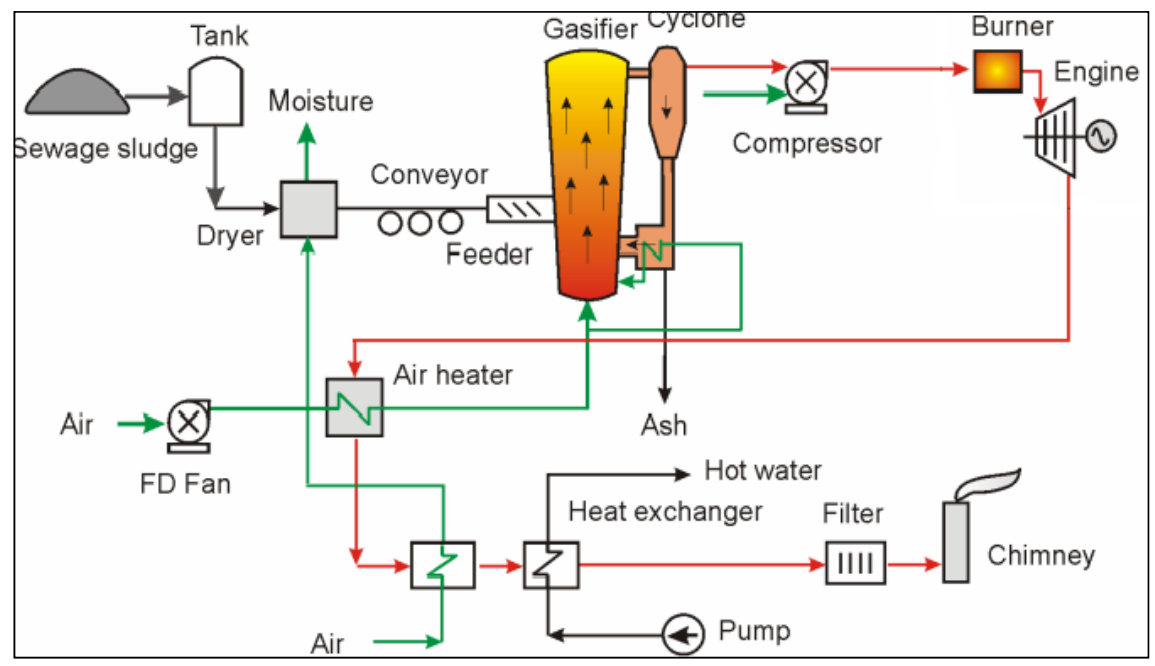

Figure 1: Gasification plant scheme.

Table 7: Energetic balance.

\begin{tabular}{|l|l|}
\hline Thermal input [MW] & 9.7 \\
\hline Net power output [MWe] & 1.75 \\
\hline Thermal output [MWth] & 4.71 \\
\hline
\end{tabular}

\subsection{Cost comparison}

If we compare the specific incineration treatment project and the literature gasification project from the point of view of the cost we can see that the obtained results are quite similar. In fact in the incineration case the capital cost referred to the plant potentiality corresponds to about $0.38 € / t / y$ (the plant capital cost is $38,500,000 €)$, while for the gasification scheme the corresponding capital is of $0.33 € / \mathrm{t} / \mathrm{y}$.

The energetic yields and the emission flow rates have not been compared because, in this case, the different quality of the different kind of sewage sludge considered is a limiting factor. The different sewage sludge quality is not, instead, a limiting parameter in the case of the cost comparison.

\section{Conclusions}

In this work we examined from the technological and environmental point of view the thermal solution (direct combustion in an incineration plant in particular, but also gasification) for the sewage sludge deriving from the main wastewater plant present in Italy. 
It is necessary to highlight that the sludge deriving from wastewater treatment plants after thermal drying is very suitable for energetic valorization processes as incineration or, in alternative, gasification processes.

In the present work after a first analysis of the state of the art necessary in order to individuate the technology of treatment and management today more suitable we performed a set of laboratory analysis in order to characterize in a complete manner, from the chemical - physical and energetic point of view the dried wastewater sludge.

With this aim we realized specific procedure in particular in order to define the content of chlorine. On the basis of these characterization required for defining the main sludge characteristics, we analyzed in detail the plant design solutions from the technical and process point of view using the tools of energy and mass balance.

Afterward we performed a comparison with a gasification solution by using a literature gasification project. We performed a comparison from a technological, energetic and economic point of view.

The work performed has a scientific valence both from punctual point of view, in connection to the specific examined case study and both a general level in fact they establish a repeatable procedure for similar management situations.

\section{References}

[1] Panepinto, D. \& Genon, G., Solid waste and biomass gasification: fundamental processes and numerical simulation, Chemical Engineering Transactions, 24, pp. 25-30, 2011.

[2] Panepinto, D. \& Genon, G., Biomass thermal treatment: energy recovery, environmental compatibility and determination of external costs, Waste and Biomass Valorization, 3, pp. 197-206, 2012.

[3] Devi, L., Ptasinski, K.J. \& Janssen, F.J.J.G., A review of the primary measures for tar elimination in biomass gasification processes, Biomass and Bioenergy, 24, pp. 125-140, 2003.

[4] Marani, D., Braguglia, C.M., Minnini, G. \& Maccioni, F., Behaviour of $\mathrm{Cd}, \mathrm{Cr}, \mathrm{Mn}, \mathrm{Ni}, \mathrm{Pb}$ and $\mathrm{Zn}$ in sewage sludge incineration by fluidised bed furnace, Waste management, 23, pp. 117-124, 2003.

[5] McCahey, S., Techno-Economic Evaluation of Sewage Sludge Gasification, $5^{\circ}$ Thermal Treatment of Sewage Sludge for CHP Applications, Brussels 15-16 September 2003.

[6] Minnini, G., Sbrilli, A., Guerriero, E. \& Rotatori, M., Dioxins and furans formation in pilot incineration tests of sewage sludge spiked with organic chlorine, Chemosphere, 54, pp. 1337-1350, 2004.

[7] Huda, M., Mochida, I., Korai, Y. \& Misawa, N., The influence of coal type on in-bed desulphurization in a PFBC demonstration plant, Fuel, 85, pp. 1913-1920, 2006.

[8] Huang, Y., Mcllveen-Wright, D., Rezvani, S., Wang, YD, Hewitt, N. \& Williams, B.C., Biomass co-firing in a pressurized fluidized bed combustion (PFBC) combined cycle power plant: A techno-environmental 
assessment based on computational simulations, Fuel Processing Technology, 87, pp. 927-934, 2006.

[9] Panepinto, D. \& Genon, G., Modeling of Po river quality in Torino (Italy), Water Resources Management, 24(12), pp. 2937-2958, 2010.

[10] Thierbach, R.D. \& Hanssen, H., Utilisation of Energy from digester and sludge incineration at Hamburg's Köhlbrandhöft WWTP.

[11] Johan te Marvelde, Valorisation of sludge incineration residuals at the DRSH Sludge Incineration Plant, DSRH Zuiveringsslib N.V.

[12] LURGI, Fluidized Bed Technology for Sludge and Residue Incineration.

[13] Luts, D., Devoldere, K., Laethem, B., Bartholomeeusen, W. \& Ockier, P., Co-incineration of dried sewage sludge in coal-fired power plants: a case study.

[14] Werther, J. \& Ogada, T., Sewage sludge combustion, Progress in Energy and Combustion Science, 25, pp. 55-116, 1999.

[15] Lin, H. \& Ma, X., Simulation of co-incineration of sewage sludge with municipal solid waste in a grate furnace incinerator, Waste Management, 32, pp. 561-567, 2012. 